\title{
Thermal treatment of coated printing and writing paper in MSW: pyrolysis kinetics
}

\author{
Chao-Hsiung $\mathrm{Wu}^{\mathrm{a}}$, Ching-Yuan Chang ${ }^{b}$, Jyh-Ping Lin ${ }^{c}$ and \\ Jiann-Yuan Hwang ${ }^{b}$ \\ ${ }^{a}$ Department of Environmental Engineering, Da-Yeh Institute of Technology, \\ Chang-Hwa 515, Taiwan \\ ${ }^{\mathrm{b}}$ Graduate Institute of Environmental Engineering, National Taiwan University, Taipei 106, \\ Taiwan

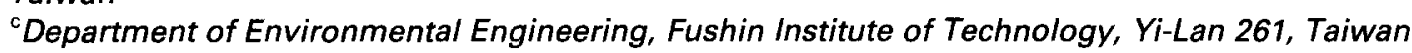 \\ (Received 14 May 1996; revised 4 April 1997)
}

\begin{abstract}
The pyrolysis kinetics of cellulosic coated printing and writing paper, a principal component of municipal solid waste (MSW) in Taiwan, were investigated by thermogravimetric analysis in nitrogen over the temperature range $450-900 \mathrm{~K}$ at heating rates of 1,2 and $5 \mathrm{~K} \mathrm{~min}^{-1}$. The t.g.a. curves indicated two principal reactions, distinguished by significant and distinct mass changes over the experimental range. The pyrolysis of coated paper could be adequately described by a two-reaction model. The corresponding activation energies, pre-exponential factors and reaction orders were determined. The experimental results were satisfactorily fitted by the proposed model. (C) 1997 Elsevier Science Ltd.
\end{abstract}

(Keywords: paper; pyrolysis kinetics; mathematical modelling)

The disposal of municipal solid waste (MSW) has become an increasingly intricate and costly problem because of the decrease in space available for landfills and growing concern about the living environment. Studies have indicated that a suitable thermal pyrolysis method may be used for resolving the disposal problems and effecting energy conversion from $\mathrm{MSW}^{1-6}$. Typically, MSW in Taiwan consists (wt\% db) of paper (26.7), cellulosic cloth (5.8), yard waste (4.4), food waste (26.9), plastics (16.9), leather and rubber (0.9), metals (6.3), glass (6.8), ceramic and earthenware materials (0.6) and miscellaneous wastes $(4.7)^{7}$. Coated printing and writing paper is one of the principal materials contributing to the MSW. Since such waste paper has a high calorific value of $\sim 11 \mathrm{MJ} \mathrm{kg}^{-1}$ (db), its conversion to marketable fuels has become a worthy goal from not only an economic but also an environmental standpoint.

There have been many studies on the pyrolysis of cellulosic materials ${ }^{8-13}$. These studies were concerned mostly with the thermal degradation of pure cellulose and focused on analysis of the products, effects of reaction conditions, mechanisms of reaction and pyrolysis kinetics etc. A number of kinetic models of the pyrolysis of cellulose have also been reported ${ }^{14-16}$. Bradbury et al. ${ }^{14}$ studied the pyrolysis of cellulose at low pressure $(700 \mathrm{~Pa})$ and proposed a three-reaction model. Their model assumed that an 'initiation reaction' led to the formation of an 'active cellulose' which subsequently decomposed via two competitive first-order reactions, one yielding volatiles and the other yielding char and a gaseous fraction. Agrawal ${ }^{15}$ also proposed a three-reaction model to simulate the pyrolysis behaviour of cellulose and to predict the yields of tar, char and gas over the temperature range $523-633 \mathrm{~K}$. His model however assumed that cellulose decomposed to tar, char and gas via three competitive first-order reactions. A modified Kilzer-Broido (K-B) model $^{17}$ was also proposed by Agrawal $^{16}$ to describe the pyrolysis of cellulose at low temperature $(<573 \mathrm{~K}$ ). According to this model, cellulose decomposed via two competitive reactions: a dehydration reaction to form anhydrocellulose and a depolymerization reaction to form levoglucosan. Anhydrocellulose later decomposed to char and gas via two competitive reactions. The results indicated that the modified $\mathrm{K}-\mathrm{B}$ model was able to describe the pyrolysis of cellulose and was more acceptable than the three-reaction model in predicting the weight loss and product yields. Other studies have used thermogravimetry to examine the degradation kinetics of newsprint in air and nitrogen ${ }^{18}$ and to explore the effects of acid washing on the pyrolysis products ${ }^{19}$. In any event, the compositions and physicochemical properties of coated printing and writing paper differ from those of newsprint (primarily made from mechanical pulp). The results of previous studies provide some knowledge of the pyrolysis kinetics of cellulose and newsprint but no kinetic data relevant to the treatment of coated printing and writing paper in MSW.

The aim of the present work was therefore to investigate coated printing and writing paper with a 
view to providing a simple kinetic model for engineering purposes. The pyrolysis of such paper was studied with a thermogravimetric analysis (t.g.a.) reaction system at various constant heating rates. The experiments were carried out over a wide temperature range (450-900 K) and in the absence of gasifying agents. Nitrogen was used as the carrier gas. The activation energies, pre-exponential factors and reaction orders of the corresponding reactions were obtained for the range of experimental conditions. A two-reaction kinetic model is proposed.

\section{EXPERIMENTAL}

\section{Materials}

Commercial-grade coated printing and writing paper was used in this study, with the properties listed in Table 1 and Table 2. The nitrogen was $99.99 \%$ pure.

\section{Pyrolysis apparatus and procedures}

A diagram of the experimental system for the pyrolysis of coated printing and writing paper is illustrated in Figure 1. An electrical balance with $0.01 \mathrm{mg}$ readability, $\leq \pm$ $0.02 \mathrm{mg}$ reproducibility and RS232 interface was used. A sample of known mass was placed on a small quartz disk $2 \mathrm{~cm}$ in diameter and $1 \mathrm{~mm}$ thick, hung on the suspension wire (platinum, $0.18 \mathrm{~mm}$ diameter) of the balance and enclosed in a quartz shell-and-tube reactor. The outer shell was $27 \mathrm{~cm}$ long with $3.8 \mathrm{~cm}$ i.d. The inner tube was $22 \mathrm{~cm}$ long with $1.2 \mathrm{~cm}$ i.d. Nitrogen at a high flow rate was first introduced into the rear channel of the balance cover for $1 \mathrm{~h}$ to purge residual oxygen. It was then adjusted to the desired flow rate and switched to the inner tube of the reactor. After $\sim 0.5 \mathrm{~h}$ the reactor was placed in the $1.28 \mathrm{~kW}$ furnace, which had been pre-set to a specified heating rate $(1,2$ or $5 \mathrm{~K} \mathrm{~min}^{-1}$ ). When the control units were all ready, the pyrolysis run was begun. The mass of sample and reaction temperature (monitored with a K-type thermocouple) during the entire pyrolysis process were recorded at time intervals of $10 \mathrm{~s}$ by the computerized data-processing unit. The pyrolysis process was operated under atmospheric pressure. The effluent stream leaving the outer shell was passed through a water trap before venting to a fume hood. When pyrolysis had ended, the furnace was turned off and nitrogen flow was maintained until the temperature of reactor was $<373 \mathrm{~K}$.

The samples were dried to constant mass at $378 \mathrm{~K}$ before starting pyrolysis at a specified heating rate. Several carrier gas flow rates and sample masses were investigated to eliminate the effects of heat and mass transfer resistances. At a sufficiently high nitrogen flow the gas film resistance to heat and mass transfer can be considered to be negligible. The results indicated that a nitrogen flow rate of $50 \mathrm{~cm}^{3} \mathrm{~min}^{-1}$ (at $101.3 \mathrm{kPa}$ and $293 \mathrm{~K}$ ) was appropriate. The effects of sample mass (2-200 mg) were investigated with polypropylene as test material in the same pyrolysis system. The results indicated that the influence of sample mass between 2 and $20 \mathrm{mg}$ on the reaction was negligible. Hence a mass of $4 \pm 0.1 \mathrm{mg}$ was used for all the experimental runs yielding kinetic data.

In general, there were thermal gradients between the sample and the environment which might change during the reaction, in the longitudinal and radial directions of the t.g.a. furnace. For this reason, the recorded temperature might not directly match the sample temperature. There are several ways to obtain the true sample temperature ${ }^{20}$. Insertion of a
Table 1 Properties of coated paper sample

\begin{tabular}{|c|c|}
\hline Composition & \\
\hline NBKP + $\operatorname{LBKP}^{a}(\%)$ & $85-$ \\
\hline Filler $\left(\mathrm{CaCO}_{3}\right)(\%)$ & $10-$ \\
\hline Coating thickness ${ }^{b}\left(\mathrm{~g} \mathrm{~m}^{-2}\right)$ & 15 \\
\hline Heating value $\left(\mathrm{MJ} \mathrm{kg}^{-1}\right)$ & \\
\hline higher & 12. \\
\hline lower & 11. \\
\hline Proximate analysis (wt\%) & \\
\hline Moisture & 0. \\
\hline Ash & 27 \\
\hline Combustibles & 71 \\
\hline
\end{tabular}

${ }^{a}$ Nadelholtz and Laubholtz bleaching kraft processes: long and short cellulose with lengths $3-5$ and $0.5-1 \mathrm{~mm}$ respectively

${ }^{b}$ Double-sided; coating material, pigment $\left(\mathrm{CaCO}_{3}\right)$ and binder (styrenebutadiene resin, SBR)

Table 2 Ultimate analyses of coated paper sample and pyrolysis residues $^{a}$

\begin{tabular}{lcrr}
\hline & \multicolumn{1}{c}{ Sample } & Residue $1^{b}$ & ${\text { Residue } 2^{c}}^{c}$ \\
\hline $\mathrm{C}$ (wt\%) & $30.5(0.2)^{d}$ & $30.7(0.2)$ & $24.1(0.1)$ \\
$\mathrm{H}(\mathrm{wt} \%)$ & $4.6(0.1)$ & $4.1(0.1)$ & $1.9(0.1)$ \\
$\mathrm{O}(\mathrm{wt} \%)$ & $37.7(0.2)$ & $33.6(0.2)$ & $16.4(0.2)$ \\
$\mathrm{N}(\mathrm{wt} \%)$ & $2.9(0.1)$ & $3.1(0.8)$ & $2.6(0.1)$ \\
$\mathrm{S}$ (wt\%) & $1.5(1.9)$ & n.d. & n.d. \\
$\mathrm{Cl}(\mathrm{wt} \%)$ & $1.5(0.4)$ & n.d. & n.d. \\
$\mathrm{Si}$ (ppmw) & 112800 & & \\
$\mathrm{Ca}$ (ppmw) & 72300 & & \\
$\mathrm{Al}$ (ppmw) & 48200 & & \\
$\mathrm{Mg}$ (ppmw) & 6780 & & \\
$\mathrm{Fe}$ (ppmw) & 4160 & & \\
$\mathrm{Cr}$ (ppmw) & 30 & & \\
$\mathrm{Mn}$ (ppmw) & 29 & & \\
$\mathrm{Zn}$ (ppmw) & $<10$ & & \\
$\mathrm{Cd}$ (ppmw) & $<10$ & & \\
$\mathrm{~Pb}$ (ppmw) & $<10$ & & \\
\hline
\end{tabular}

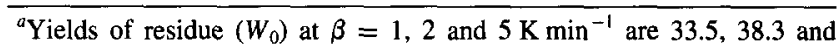
$38.1 \mathrm{wt} \%$ respectively

${ }^{b}$ From pyrolysis at $\sim 670 \mathrm{~K}$ at $\beta=5 \mathrm{~K} \mathrm{~min}^{-1}$

${ }^{c}$ From pyrolysis at $\sim 850 \mathrm{~K}$ at $\beta=5 \mathrm{~K} \mathrm{~min}^{-1}$

${ }^{d}$ Figures in parentheses are standard deviations

Not detected

temperature probe directly into the sample could reduce the accuracy of weighing of samples. Instead, the sample was well dispersed and homogenized at the centre of the disk and the temperature was taken at $3 \mathrm{~mm}$ radially near the disk centre and $2 \mathrm{~mm}$ longitudinally above the sample in all experiments. The temperature gradients were measured by locating the thermocouple at different positions external to the sample in the longitudinal and radial directions of the t.g.a. furnace. The results showed that the longitudinal temperature gradients were $<0.5 \mathrm{~K} \mathrm{~mm}^{-1}$ at all three heating rates, and the radial temperature gradients were $\sim 0.33,0.36$ and $0.44 \mathrm{~K} \mathrm{~mm}^{-1}$ at heating rates of 1,2 and $5 \mathrm{~K} \mathrm{~min}^{-1}$ respectively. Thus the sample temperature was closely represented by the measured temperature.

Elemental compositions were determined with instrumental analysers for $\mathrm{C}, \mathrm{H}, \mathrm{N}, \mathrm{S}, \mathrm{O}$ and $\mathrm{Cl}$. The standard deviation varied with the element. Inductively coupled plasma atomic emission spectrometry was used to quantify some major metals in the paper sample.

\section{RESULTS AND DISCUSSION}

\section{Effect of temperature and heating rate}

The residue with a mass of $W$ after pyrolysis was 


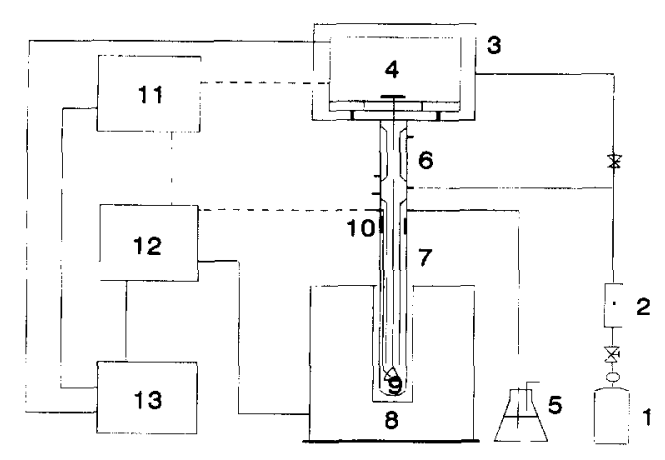

Figure 1 Schematic diagram of apparatus for pyrolysis of coated printing and writing paper. 1 , Nitrogen; 2 , flowmeter with needle valve; 3 , cover; 4 , electrobalance; 5 , trap; 6 , condenser; 7 , shelland-tube reactor; 8 , furnace; 9 , sample and pan; 10, K-type thermocouple; 11, computer for data processing; 12, temperature controller; 13 , power supply

expressed on a normalized basis as residual mass fraction $M=\left(W-W_{\mathrm{f}}\right) /\left(W_{0}-W_{\mathrm{f}}\right)$. The variation of $M$ with reaction temperature $(T)$ at the three heating rates $(\beta)$ is shown in Figure 2. Obviously there were two principal reactions, distinguished by the two significant and distinct mass changes over the temperature range $450-900 \mathrm{~K}$ for all three heating rates. When the temperature reached $\sim 500 \mathrm{~K}$, the first distinct mass change began and proceeded very slowly when the residual mass fraction $(M)$ exceeded 0.9 . When $M$ fell below 0.9 , the mass change proceeded rapidly until $M$ was $\sim 0.2$ and then slowly. The second distinct mass change began at a residual mass fraction of $\sim 0.19$ and proceeded slowly to the end. The final residual masses $\left(W_{f}\right)$ were $\sim 33.5,38.3$ and $38.1 \%$ of $W_{0}$ at heating rates of 1,2 and $5 \mathrm{~K} \mathrm{~min}^{-1}$ respectively. At a lower heating rate, the time required for the polymer to reach a given temperature was longer. This would generally result in a higher conversion (a lower value of $M$ ). Hence the residual-mass curve at a lower heating rate is below or to the left of that at a higher heating rate.

\section{Reaction rate}

The degradation rates $r=\mathrm{d} X / \mathrm{d} t$, with conversion $X=$ $\left(W_{0}-W\right) /\left(W_{0}-W_{f}\right)$, of coated printing and writing paper at heating rates of 1,2 and $5 \mathrm{~K} \mathrm{~min}^{-1}$ are shown in Figure 3. The temperature of maximum rate varied with the heating rate. A higher heating rate shifted the curve to a higher temperature range, and also resulted in a higher peak rate.

\section{Activation energy}

Some common methods used for computing the activation energy ( $E$ ) have been developed by previous investigators $^{21-23}$. These methods were primarily based on the equation:

$$
\mathrm{d} X / \mathrm{d} t=k f(X)
$$

where $k$ is the reaction rate constant, $k=A \exp (-E / R T)$, and $f(X)$ is a function of conversion $X$.

In this paper, the Ozawa method ${ }^{21}$ was used to calculate the activation energy $(E)$ :

$$
E=R \log \left(\beta_{2} / \beta_{1}\right) / 0.457\left[\left(1 / T_{1}\right)-\left(1 / T_{2}\right)\right]
$$

where $\beta$ is the heating rate, $T$ is the pyrolysis temperature and the subscripts 1 and 2 denote different heating rates or pyrolysis temperatures.

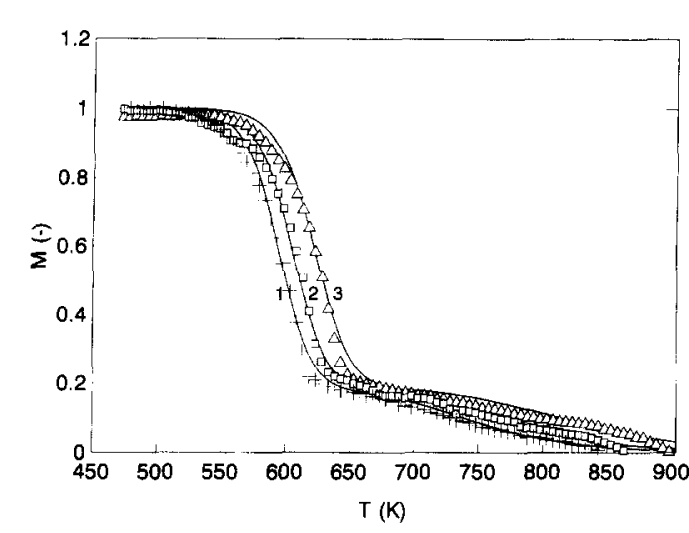

Figure 2 Comparison of predicted curves (- $\longrightarrow$ ) of residual mass fraction $(M)$ versus pyrolysis temperature with experimental data $(+, \square, \Delta)$ at heating rates $(\beta)$ of $1(+, 1), 2(\square, 2)$ and $5(\Delta, 3)$

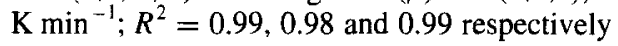

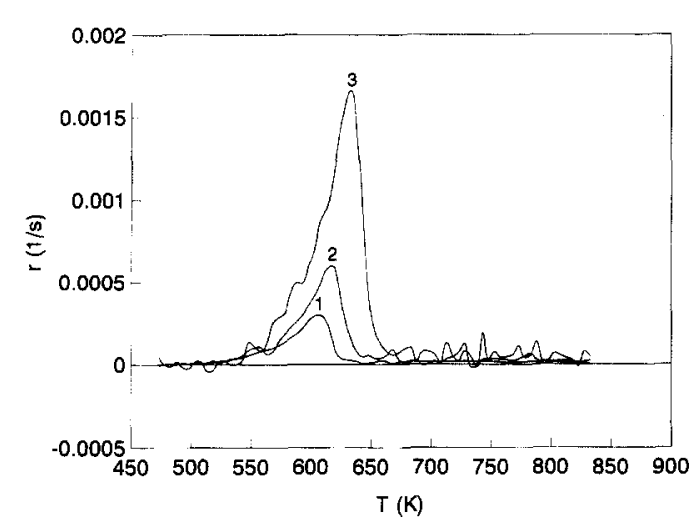

Figure 3 Variation of instantaneous reaction rate $(r=\mathrm{d} X / \mathrm{d} t)$ with $T$ at heating rates $(\beta)$ of $1(1), 2(2)$ and $5(3) \mathrm{K} \mathrm{min}^{-1}$

At the same degree of conversion, the reaction temperatures were different at different heating rates. A desired residual mass fraction (or conversion) was specified from Figure 2, and then the reaction temperatures corresponding to the various heating rates were obtained. The activation energy corresponding to the selected conversion could then be computed by substituting the resulting temperatures and heating rates into eqn (2).

The activation energies at different conversions are illustrated in Figure 4. The results indicated that the activation energies of the pyrolysis of coated printing and writing paper were in the range $\sim 90-210 \mathrm{~kJ} \mathrm{~mol}^{-1}$. These values may be divided into two groups, namely 160 $210 \mathrm{~kJ} \mathrm{~mol}^{-1}$ for $X=0.1-0.78$, and $90-190 \mathrm{~kJ} \mathrm{~mol}^{-1}$ for $X$ $=0.78-0.99$.

\section{KINETIC MODEL}

The paper considered consists mostly of cellulose together with a small fraction of hemicellulose, $\mathrm{CaCO}_{3}$, additives, coating materials [pigment $\left(\mathrm{CaCO}_{3}\right)$ and binder (styrenebutadiene resin, SBR)] and impurities. As the main component, cellulose itself is composed of d-glucose units $\left(\mathrm{C}_{6} \mathrm{H}_{10} \mathrm{O}_{5}\right)$ bonded together by ether-type linkages called glycosidic bonds ${ }^{24}$. Owing to these linkages, the cellulose 


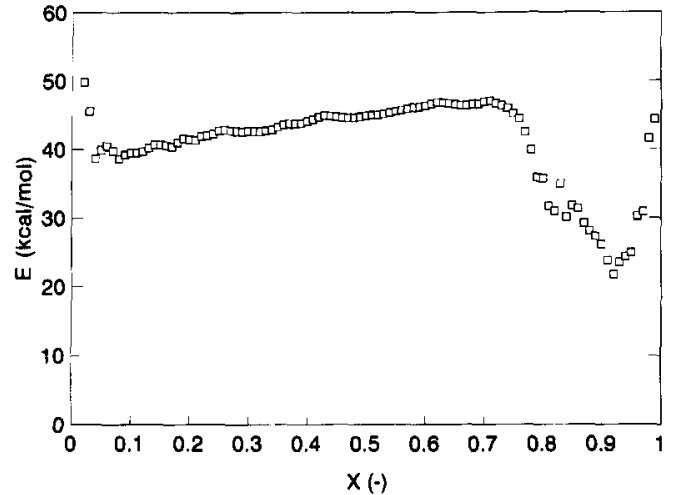

Figure 4 Computed activation energies $(E)$ at different conversions $(X)$, using results at heating rates of 1,2 , and $5 \mathrm{~K} \mathrm{~min}^{-1}$
The t.g.a. curves show that there were two principal reactions as distinguished by the two significant and distinct mass changes over the temperature range $450-900 \mathrm{~K}$. Figure 2 suggests that the first pyrolysis reaction contributed mainly in the temperature range below $\sim 630$ $675 \mathrm{~K}$. The residual mass fraction of the pyrolysed sample decreased from 1.0 to $\sim 0.19$ at all three heating rates. The degradation reactions of cellulose, hemicellulose and SBR etc. of coated printing and writing paper were considered as an overall reaction. The products of this reaction were intermediates and volatiles (gaseous at the pyrolysis temperature). The second reaction contributed mainly in the temperature range from $\sim 630-675$ to $900 \mathrm{~K}$. In this reaction, the intermediates further reacted to form volatiles and solid residue. The decomposition of intermediates was also considered as a representative reaction.

A two-reaction model is therefore proposed here to represent the pyrolysis of coated printing and writing paper as:
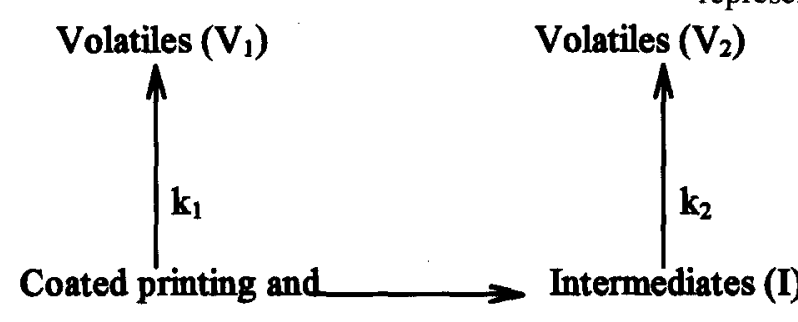

\section{writing paper (P)}

polymers form very long threadlike chains of molecular weight $>100000$. In addition, there is hydrogen bonding between hydroxyl hydrogen and ring oxygen in the adjacent monomer, and strong van der Waals forces or hydrogen bonds between threads, giving rise to a lamellar structure. Cellulose fibres are therefore very strong. Most hemicelluloses contain two to four (and occasionally five or six) simpler sugar residues ${ }^{24}$. d-Xylose, d-glucose, d-mannose, d-galactose, 1-arabinose, d-glucuronic acid and 4-Omethyl-d-glucuronic acid residues constitute the majority of hemicellulose monomers, of which d-xylose $\left(\mathrm{C}_{5} \mathrm{H}_{10} \mathrm{O}\right)$ is the most abundant. The structure of hemicellulose is similar to that of cellulose except that its polymers generally contain 50-200 units, fewer than those of cellulose, and exhibit a branched rather than a linear structure. Hemicellulose is known to be less thermally stable than cellulose in view of its molecular structure.

Generally, the pyrolysis of coated printing and writing paper would comprise a complex series of concurrent/ consecutive chemical decomposition reactions of cellu$\operatorname{lose}^{17}$, depolymerization of hemicellulose $\mathrm{e}^{24}$ and degradation of SBR. The presence of additives and inorganic impurities may affect the pyrolysis rate. Owing to the variety of components in paper, its pyrolysis behaviour may differ significantly from that of pure cellulose or hemicellulose. In addition, the molecular structure of the residue may vary during pyrolysis and differ from the original one. The reaction mechanisms and the corresponding kinetic parameters for the pyrolysis of various intermediate residues may also differ from those for the parent. It is therefore difficult to determine the kinetic parameters for the pyrolysis reactions with a large variety of intermediate residues from the t.g.a. curves only. Fortunately the numerous reactions may be simplified and lumped to a more briefly representative reaction pattern for the determination of kinetic expressions for the pyrolysis of coated printing and writing paper. where $\mathrm{P}, \mathrm{I}$ and $\mathrm{C}$ represent the coated printing and writing paper, the intermediates and the solid residues respectively. $V_{1}$ and $V_{2}$ are the volatiles released from the pyrolysis of coated printing and writing paper (P) and the intermediates (I) respectively.

Based on the proposed model and the Arrhenius law, the residual mass fraction $M$ may be obtained from the following equations:

$$
\begin{aligned}
& M=\left(W-W_{\mathrm{f}}\right) /\left(W_{0}-W_{\mathrm{f}}\right)=1-m_{\mathrm{v} 1}-m_{\mathrm{v} 2} \\
& \mathrm{~d}\left(m_{\mathrm{v} 1} / F_{1}\right) / \mathrm{d} t=k_{1}\left[1-\left(m_{\mathrm{v} 1} / F_{1}\right)\right]^{n_{1}} \\
& \mathrm{~d}\left(m_{\mathrm{v} 2} / F_{2}\right) / \mathrm{d} t=k_{2}\left[1-\left(m_{\mathrm{v} 2} / F_{2}\right)\right]^{n_{2}}
\end{aligned}
$$

where $k_{1}=A_{1} \exp \left(-E_{1} / R T\right)$ and $n_{1}$, and $k_{2}=A_{2} \exp \left(-E_{2} /\right.$ $R T)$ and $n_{2}$, are the Arrhenius rate constants and reaction orders of reactions 1 and 2 respectively, and $m_{\mathrm{v} 1}=W_{\mathrm{v} 1} l$ $\left(W_{0}-W_{\mathrm{f}}\right)$ and $m_{\mathrm{v} 2}=W_{\mathrm{v} 2} /\left(W_{0}-W_{\mathrm{f}}\right)$ are the mass fractions of volatiles $V_{1}$ and $V_{2}$ respectively. Eqns (3)-(5) satisfy the following conditions:

$$
M=1, m_{\mathrm{v} 1}=m_{\mathrm{v} 2}=0 \quad \text { at } t=0
$$

In eqns (4) and (5), $F_{1}$ and $F_{2}$ are weighting factors taking account of the decrease in residual mass fraction contributed by pyrolysis reactions $1(<630-675 \mathrm{~K})$ and $2(630-675$ to $900 \mathrm{~K}$ ) respectively. From the t.g.a. curves of Figure $2, F_{1}$ and $F_{2}$ are estimated to be $\sim 0.81$ and $\sim 0.19$ respectively.

Eqns (4) and (5) were solved to give the following solutions:

$$
\begin{aligned}
& m_{\mathrm{v} l} / F_{1} \approx 1-\left\{\left[A_{1} R T^{2}\left(n_{1}-1\right)\left(1-2 R T / E_{1}\right)\right.\right. \\
& \left.\left.\quad \times \exp \left(-E_{1} / R T\right)\right] / E_{1} \beta+1\right\}^{1 /\left(1-n_{1}\right)}, \quad n_{1} \neq 1 \\
& \approx 1-\exp \left\{-\left[A_{1} R T^{2}\left(1-2 R T / E_{1}\right)\right.\right. \\
& \left.\left.\quad \times \exp \left(-E_{1} / R T\right)\right] / E_{1} \beta\right\}, \quad n_{1}=1
\end{aligned}
$$




$$
\begin{aligned}
& m_{\mathrm{v} 2} / F_{2} \approx 1-\left\{\left[A_{2} R T^{2}\left(n_{2}-1\right)\left(1-2 R T / E_{2}\right)\right.\right. \\
& \left.\left.\quad \times \exp \left(-E_{2} / R T\right)\right] / E_{2} \beta+1\right\}^{1 /\left(1-n_{2}\right)}, \quad n_{2} \neq 1 \\
& \approx \\
& \quad 1-\exp \left\{\left[-\left[A_{2} R T^{2}\left(1-2 R T / E_{2}\right)\right.\right.\right. \\
& \left.\left.\quad \times \exp \left(-E_{2} / R T\right)\right] / E_{2} \beta\right\}, \quad n_{2}=1
\end{aligned}
$$

where $\beta=\mathrm{d} T / \mathrm{d} t$ is the heating rate, $A_{1}$ and $E_{1}$, and $A_{2}$ and $E_{2}$, are the pre-exponential factors and activation energies of pyrolysis reactions 1 and 2 respectively, and $T$ is the pyrolysis temperature.

In this study, the parameters $E, A$ and $n$ were obtained by using the results at heating rates of 1,2 and $5 \mathrm{~K} \mathrm{~min}^{-1}$. Since the values of activation energy varied with the extent of reaction (as shown in Figure 4), it was necessary to select a set of representative kinetic parameters in applying eqns (7)-(10) for engineering purposes. The activation energies for pyrolysis reactions 1 and 2 were obtained by taking arithmetic averages over the conversion ranges $X=0.2-0.6$ and $X=0.86-0.96$ respectively. This gave $E_{1}=$ $182 \mathrm{~kJ} \mathrm{~mol}^{-1}$ and $E_{2}=105 \mathrm{~kJ} \mathrm{~mol}^{-1}$ (Table 3) with standard deviations of 5 and $8 \mathrm{~kJ} \mathrm{~mol}^{-1}$ respectively. Also, rearranging eqn (1) with $f(X)=(1-X)^{n}$ and taking natural logarithms gives:

$$
\ln [(\mathrm{d} X / \mathrm{d} t) / \exp (-E / R T)]=\ln A+n \ln (1-X)
$$

With the substitution of the instantaneous rates (obtained from Figure 3) and the activation energy (182 or $105 \mathrm{~kJ} \mathrm{~mol}^{-1}$ ) into eqn (11), a straight line with slope $n$ and intercept $\ln A$ was obtained by plotting $\ln [(\mathrm{d} X / \mathrm{d} t) / \mathrm{exp}$ $(-\mathrm{E} / \mathrm{RT})]$ against $\ln (1-X)$. Thus the pre-exponential factors and the reaction orders were obtained as listed in Table 3 . The reaction orders of 1.5 and 2.0 for pyrolysis reactions 1 and 2 respectively indicate that the pyrolysis of coated printing and writing paper can be described by eqns (3)(7) and (9). Published activation energies, reaction orders and pre-exponential factors for pyrolysis of cellulose, waste paper and newsprint are of the same magnitude as those obtained in this analysis, and are listed in Table $4^{25}$ for reference. The variations in the computed values of $m_{\mathrm{v} 1}$ and $m_{\mathrm{v} 2}$ versus $\mathrm{T}$ (at $\beta=5 \mathrm{~K} \mathrm{~min}^{-1}$ ) are shown in Figure 5 . The release of volatiles $V_{2}$ by pyrolysis reaction 2 is significant from $630-675$ to $900 \mathrm{~K}$, while that of volatiles $V_{1}$ by pyrolysis reaction 1 is significant from 500 to $630-$ $675 \mathrm{~K}$. The variations in the computed $m_{\mathrm{v} 1}$ and $m_{\mathrm{v} 2}$ with temperature thus reasonably indicate the two distinct changes in $M$ : one from 500 to $630-675 \mathrm{~K}$ and the other from $630-675$ to $900 \mathrm{~K}$.

To verify the applicability of the kinetic parameters obtained and the validity of the proposed kinetic model for the entire process of pyrolysis, the values of residual mass fraction computed by the proposed kinetic model were compared with the experimental data, as shown in Figure 2. The coefficients of determination, $R_{1}^{2}, R_{2}^{2}$ and $R_{3}^{2}$ (computed for the range 5-95\% of final weight loss, $W_{0}-W_{f}$ ), of these curves of $\beta_{1}, \beta_{2}$, and $\beta_{3}$ were $0.99,0.98$ and 0.99 respectively. The results computed by the proposed model gave good agreement with the experimental data. This thus supports the validity and practical applicability of the proposed kinetic model, with no detailed chemical composition of pyrolysis products. However, further work would help to support the applicability of the present model. Such work may include: (1) closer consideration of the environment in an MSW incinerator, where the bed materials are heated to the boiling point of water and remain there for a
Table 3 Kinetic parameters ${ }^{a}$ of pyrolysis reactions 1 and 2 for coated paper

\begin{tabular}{lcc} 
& Reaction 1 & Reaction 2 \\
\hline Activation energy, $E\left(\mathrm{~kJ} \mathrm{~mol}^{-1}\right)$ & 182 & 105 \\
Reaction order, $n$ & 1.5 & 2 \\
Pre-exponential factor, A (s $\left.{ }^{-1}\right)$ & $8.9 \times 10^{12}$ & 9800 \\
Weighting factor, $F$ & 0.81 & 0.19 \\
\hline
\end{tabular}

${ }^{a}$ Estimated over the conversion ranges $X=0.4-0.6$ and $X=0.85-0.95$ for reactions 1 and 2 respectively, using the results at heating rates of 1,2 and $5 \mathrm{~K} \mathrm{~min}^{-1}$

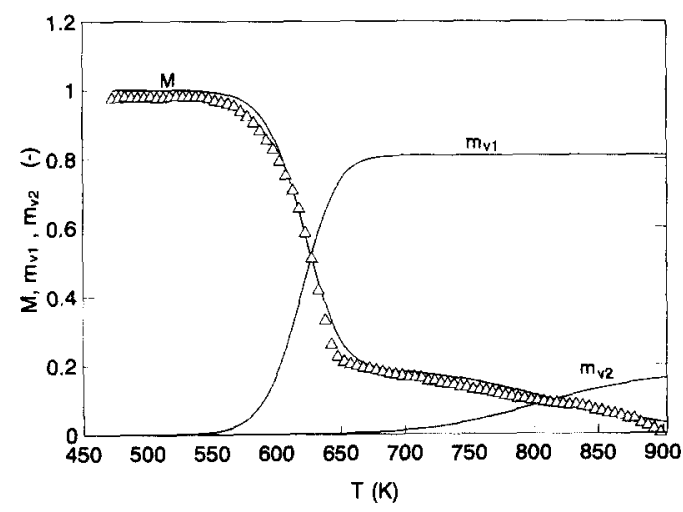

Figure 5 Computed values $(\longrightarrow)$ and experimental data $(\Delta)$ of residual mass fraction $(M)$, and computed values (- $\longrightarrow$ of mass fractions of volatiles $V_{1}\left(m_{\mathrm{v} 1}\right)$ and $V_{2}\left(m_{\mathrm{v} 2}\right)$ predicted from proposed model at $\beta=5 \mathrm{~K} \mathrm{~min}^{-1}$

period before again increasing in temperature; (2) analysis in detail of the pyrolysis products to ascertain the variations with pyrolysis temperatures and the compositions of products at specified temperatures; (3) experiments with cellulose and/or MSW in the presence of oxygen and at higher heating rates; (4) checking of the applicability of the model parameters $F_{1}$ and $F_{2}$ with different sample sizes. Also, the inorganic components as listed in Table 2 could have catalytic effects on pyrolysis. Controlled experiments would be needed to elucidate these effects.

\section{CONCLUSIONS}

Thermogravimetry of coated printing and writing paper revealed two distinct pyrolysis reaction stages, distinguished by different rates of mass loss at temperatures of 500 to $630-675 \mathrm{~K}$ and $630-675$ to $900 \mathrm{~K}$. A two-reaction kinetic model representing the process gave good agreement with the experimental data. Activation energies, preexponential factors and orders of reaction computed from the model were comparable with published values for cellulose pyrolysis. The data and model appear to be useful in the design of MSW processing systems.

\section{ACKNOWLEDGEMENTS}

The authors express sincere thanks to the National Science Council of ROC, Taiwan for financial support under projects NSC 80-0410-E-002-70, 81-0421-E-002-531 and 82-0410-E-002-329. They would also like to thank the Yuen Foong Yu Co. Ltd of Taiwan for providing the coated printing and writing paper sample. 
Table 4 Kinetic parameters for pyrolysis of cellulose, cellulosic materials and paper in MSW in the literature ${ }^{a}$

\begin{tabular}{|c|c|c|c|c|c|c|}
\hline Material & Reference & Method & Condition & $\begin{array}{l}\text { Activation energy } \\
\left(\mathrm{kJ} \mathrm{mol}^{-1}\right)\end{array}$ & Reaction order & $\begin{array}{l}\text { Pre-exponential factor } \\
\qquad\left(s^{-1}\right)\end{array}$ \\
\hline Cellulose (powder) & 8 & t.g.a. & in $N_{2}, 548-615 \mathrm{~K}$ & 220 & - & $2.52 \times 10^{16}$ \\
\hline \multirow[t]{3}{*}{ Cellulose } & 14 & t.g.a. & $\begin{array}{c}\text { in } \mathrm{N}_{2}, 532-614 \mathrm{~K} \\
700 \mathrm{~Pa}\end{array}$ & $243^{b}$ & 1 & $1.7 \times 10^{21}$ \\
\hline & & & & $198^{b}$ & 1 & $1.9 \times 10^{16}$ \\
\hline & & & & $153^{b}$ & 1 & $7.9 \times 10^{11}$ \\
\hline \multirow[t]{2}{*}{ Cellulose (filter paper) } & 10 & t.g.a. & in $N_{2},<87 \overline{3} \mathrm{~K}$ & 153 & 0.46 & $6.06 \times 10^{9}$ \\
\hline & & & in steam, $<873 \mathrm{~K}$ & 143 & 0.51 & $1.67 \times 10^{9}$ \\
\hline \multirow{3}{*}{$\begin{array}{l}\text { Waste paper ( } 99 \% \\
\text { newsprint) }\end{array}$} & 18 & t.g.a. & in $N_{2},<753 \mathrm{~K}$ & 163 & 2 & $1.8 \times 10^{11}$ \\
\hline & & & in air, $<753 \mathrm{~K}$ & $174^{c}$ & 2 & $1.2 \times 10^{13}$ \\
\hline & & & & $163^{c}$ & - & $6.7 \times 10^{8}$ \\
\hline Newsprint & 19 & - & $\begin{array}{c}\text { in } \mathrm{N}_{2}, 533-613 \mathrm{~K} \\
<100 \mathrm{~Pa}\end{array}$ & 104 & - & $1.5 \times 10^{7}$ \\
\hline \multirow[t]{3}{*}{ Cellulose } & 15 & fluidized bed & in $\mathrm{N}_{2}, 523-633 \mathrm{~K}$ & $211 \pm 6^{d}$ & 1 & $2.0 \times 10^{15}$ \\
\hline & & & & $192 \pm 6^{d}$ & 1 & $1.4 \times 10^{13}$ \\
\hline & & & & $187 \pm 5^{d}$ & 1 & $7.8 \times 10^{12}$ \\
\hline \multirow[t]{4}{*}{ Cellulose } & 16 & fluidized bed & in $\mathrm{N}_{2}, 523-571 \mathrm{~K}$ & $196 \pm 7^{e}$ & 1 & $1.1 \times 10^{14}$ \\
\hline & & & & $159 \pm 10^{e}$ & 1 & $3.0 \times 10^{10}$ \\
\hline & & & & $204 \pm 11^{e}$ & 1 & $3.2 \times 10^{14}$ \\
\hline & & & & $215 \pm 13^{e}$ & 1 & $5.7 \times 10^{15}$ \\
\hline \multirow[t]{2}{*}{ Cellulose } & 12 & t.g.a. & in $\mathrm{N}_{2}, 207-315 \mathrm{~K}$ & $78-102$ & $0-0.09$ & - \\
\hline & & & $305-355 \mathrm{~K}$ & $148-259$ & $0.69-0.92$ & - \\
\hline
\end{tabular}

${ }^{a}$ This table was previously published in ref.25

${ }^{b}$ Top to bottom, the three values are for the reactions cellulose $\rightarrow$ active cellulose, active cellulose $\rightarrow$ volatiles and active cellulose $\rightarrow$ char + gas respectively ${ }^{c}$ Upper and lower values are for the first and second reaction steps respectively

${ }^{d}$ Top to bottom, the three values are for the reactions cellulose $\rightarrow$ tar, cellulose $\rightarrow$ gas and cellulose $\rightarrow$ char + gas respectively

${ }^{e}$ Top to bottom, the four values are for the reactions cellulose $\rightarrow$ tar, cellulose $\rightarrow$ anhydrocellulose, anhydrocellulose $\rightarrow$ char and anhydrocellulose $\rightarrow$ gas respectively

\section{REFERENCES}

1 Hoffman, D. A. and Fitz, R. A., Environmental Science and Technology, 1968, 2, 1023.

2 Buekens, A. G. and Schoeters, J. G., Conservation and Recycling, 1986, 9, 253.

3 Aroğuz, A. Z. and Önsan, Z. I., Chimica Acta Turcica, 1987, $15,415$.

4 Levie, B., Diebold, J. P. and West, R. in Research on Thermochemical Biomass Conversion, ed. A. V. Bridgwater and J. L. Kuester. Elsevier, London, 1988, pp. 312-326.

5 Mallya, N. and Helt, J. E., in Proceedings of the 13th National Waste Process Conference, USA. 1988, pp. 295300 .

6 Diebold, J., Evans, R. and Scabill, J., Energy from Biomass and Wastes, 1990, 13, 851.

7 Yang, W. F., An engineering project for garbage incineration plant of Taipei City: sampling and analysis of garbage at eleventh year. Report of Environmental Protection Burean of Taipei City, Taiwan, ROC, 1994.

8 Fairbridge, C., Ross, R. A. and Sood, S. P., Journal of Applied Polymer Science, 1978, 22, 497.

9 Shafizadeh, F. and Bradbury, A. G. W., Journal of Applied Polymer Science, 1979, 23, 1431.

10 Antal, M. J., Friedman, H. L. Jr and Rogers, F. E., Combustion Science and Technology, 1980, 21, 141.

11 Šimkovic, I., Ďurindová, M., Mihálov, V. and Königstein, J., Journal of Applied Polymer Science, 1986, 31, 2433.

12 Calahorra, M. E., Cortázar, M., Eguiazábal, J. I. and Guzmán, G. M., Journal of Applied Polymer Science, $1989,37,3305$.

13 Gullett, B. K. and Smith, P., Combustion and Flame, 1987, 67, 143.

14 Bradbury, A. G. W., Sakai, Y. and Shafizadeh, F., Journal of Applied Polymer Science, 1979, 23, 3271.

15 Agrawal, R. K., Canadian Journal of Chemical Engineering, 1988, 66, 403.

16 Agrawal, R. K., Canadian Journal of Chemical Engineering, 1988, 66, 413.

17 Kilzer, F. J. and Broido, A., Pyrodynamics, 1965, 2, 151.
18 Rogers, F. E. and Ohlemiller, T. J., Combustion Science and Technology, 1980, 24, 129.

19 Agrawal, R. K. and McCluskey, R. J., Journal of Applied Polymer Science, 1983, 27, 367.

20 Nguyen, T., Zavarin, E. and Barrall, E. M. II, Journal of Macromolecular Science C: Reviews of Macromolecular Chemistry, 1981, C20, 1.

21 Ozawa, T., Bulletin of the Chemical Society of Japan, 1965, 38, 1881.

22 Nishizaki, H., Joumal of Applied Polymer Science, 1980, 25, 2869.

23 Petrovic, Z. S. and Zavargo, Z. Z., Joumal of Applied Polymer Science, 1986, 32, 4353.

24 Reed, T. B., Biomass Gasification Principles and Technology, Noyes Data Corporation, Park Ridge, NJ, 1981.

25 Chang, C. Y., Wu, C. H., Hwang, J. Y., Lin, J. P., Yang, W. F., Shin, S. M., Chen, L. W. and Chang, F. W., Journal of Environmental Engineering, 1996, 122, 299.

\section{NOMENCLATURE}

pre-exponential factor of Arrhenius equation $\left(\mathrm{s}^{-1}\right)$
solid residue from reaction 2
activation energy $\left(\mathrm{kJ} \mathrm{mol}^{-1}\right)$
weighting factor taking account of contribution of
pyrolysis reaction 1 or 2
intermediate product from reaction 1
Arrhenius reaction rate constant, $=A \exp (-E / R T)$
$\left(\mathrm{s}^{-1}\right)$
residual mass fraction at time $t,=\left(W-W_{\mathrm{f}}\right) /\left(W_{0}-W_{\mathrm{f}}\right)$
mass fraction of volatiles $\mathrm{V},=W_{\mathrm{v}} /\left(W_{0}-W_{\mathrm{f}}\right)$
reaction order
coated printing and writing paper
molar gas constant, $8.315 \mathrm{~J}$ mol
coefficient of determination, $\mathrm{K}^{-1}=$
$1-\left[\Sigma(y-\hat{y})^{2}\right] /\left[\Sigma(y-\bar{y})^{2}\right]$
instantaneous reaction rate, $=\mathrm{d} X / \mathrm{d} t\left(\mathrm{~s}^{-1}\right)$
pyrolysis temperature $(\mathrm{K})$
pyrolysis time, $=\left(T-T_{0}\right) / \beta(\mathrm{s})$
volatiles produced by pyrolysis
total mass of sample at time $t(\mathrm{mg})$


$W_{v} \quad$ cumulative mass of volatiles at time $t(\mathrm{mg})$

$X \quad$ fractional conversion at time $t,=\left(W_{0}-W\right) /\left(W_{0}-W_{\mathrm{f}}\right)$

$=1-M=m_{\mathrm{v} 1}+m_{\mathrm{v} 2}$

experimental value of residual mass fraction at specified temperature

$\hat{y} \quad$ computed value of residual mass fraction at specified temperature

arithmetic average of experimental values of residual mass fractions at specified temperature

\section{Subscripts}

1,2

1,2

$1,2,3$ initial value

(applied to $A, E, F, k, m_{v}, n, V, W$ ) pyrolysis reactions 1 and 2

(applied to $T$ ) different temperatures

(applied to $\beta$ ) rates of 1,2 and $5 \mathrm{~K} \mathrm{~min}^{-1}$ respectively final

\section{Greek symbols}

heating rate, $=\mathrm{d} T / \mathrm{d} t\left(\mathrm{~K} \mathrm{~min}^{-1}\right)$ 